\title{
Dual solutions of exponentially stretched/shrinked flows of nanofluids
}

\begin{abstract}
An analysis is made of a steady two-dimensional boundary layer flow of a nanofluid and heat transfer over a stretching/shrinking sheet. The governing boundary layer equations are reduced into ordinary differential equations by a similarity transformation which are then solved numerically for three types of nanoparticles, namely copper $(\mathrm{Cu})$, alumina $\left(\mathrm{Al}_{2} \mathrm{O}_{3}\right)$, and titania $\left(\mathrm{TiO}_{2}\right)$ in the water based fluid with Prandtl number $\operatorname{Pr}=6.2$. The model used for the nanofluid incorporates the effect of nanoparticles volume fraction $\phi$ and stretching/shrinking parameter $\lambda$. The skin friction coefficient, the local Nusselt number and the velocity and temperature profiles are presented graphically and discussed. It was found that the dual solutions exist in a certain range of the suction parameter for both stretching and shrinking cases. The nanoparticle volume fraction $\phi$ and the types of nanoparticles play an important role to significantly determine the flow behavior. It is also found that the range of the mass suction parameter $S$ where the similarity solution exists for the steady twodimensional boundary flow over an exponentially stretching/shrinking sheet is larger compared with the linear stretching/shrinking sheet case.
\end{abstract}

Keyword: Boundary layer; Dual solutions; Exponentially stretching/shrinking; Heat transfer; Nanofluids 